\title{
Faecal score and dry matter content after feeding synbiotics to neonatal Jersey crossbred calves
}

\author{
J Sahu ${ }^{1}$, S Rai ${ }^{1}$, R Behera ${ }^{1}$, S Mandal ${ }^{2}$, R Jas $^{2}$, MK Ghosh $^{1}$, DK Mandal ${ }^{1}$ and A Chatterjee ${ }^{1}$
}

Received: 01 March 2020 / Accepted: 17 April 2020 / Published online: 12 July 2020

(C) Indian Dairy Association (India) 2020

\begin{abstract}
In order to observe the effect of synbiotic feeding to neonatal calves (treatment group) for 42 days, the fecal score ranged from 1 to 3 with weekly variation $(\mathrm{p}<0.01)$ among the calves. No difference was found in the fecal score and dry matter percent in both the groups control (synbiotic not fed) and treatment (synbiotic fed) calves. However, the faecal score was negatively correlated $(\mathrm{r}=-0.564, \mathrm{P}<0.01)$ to the dry matter percent in faeces. Bacterial (Lactobacillus sp.) load count recovered from faeces was negatively correlated ( $\mathrm{r}=-0.072)$ to the FS (faecal score improved) and positively correlated ( $\mathrm{r}=0.012$ ) to the DM percent in faeces. Therefore, faecal score and dry matter in faeces was better in calves fed synbiotics and Lactobacillus $s p$. persist $(\mathrm{P}<0.01)$ to be recovered from feces even after the post feeding period of synbiotics (43-90 days).
\end{abstract}

Keywords: Faecal score, Fecal dry matter, Lactobacillus rhamnosus NCDC 298, Synbiotics,

Calves are susceptible to diarrhoea predominantly during the second week of life (Moran 2002). On feeding synbiotics, it is known to increase feed intake, body weight gain, milk digestibility, improve faecal consistency (Pranckute et al. 2016; Marcondes et al. 2016) with decreased coliform count and increase in IgG level in neonatal calves (Roodposhti and Dabiri, 2012). Accordingly,

${ }^{1}$ ICAR- National Dairy Research Institute (NDRI), Eastern Regional Station, Kalyani- 741235, West Bengal, India

${ }^{2}$ West Bengal University of Animal and Fishery Sciences, 37 \& 68 Kshudiram Bose Sarani, Kolkata - 700 037, West Bengal, India

S Rai $(\bowtie)$

ICAR- National Dairy Research Institute (NDRI), Eastern Regional Station, Kalyani- 741235, West Bengal, India

Email: drsaroj.rai@gmail.com
L. rhamnosus NCDC 298 in combination with FOS was found to be effective against toxin produced by E. coli (Anand et al. 2017) and was effective in preventing secretory diarrhoea in vitro (Mandal and Anand 2016). Therefore, subjective observation has been an important tool to assess severity of diarrhoea in young calves. Faecal scoring on 1 to 4 point scale increases numerically with the fluid content widely been used in a variety of studies (Moore et al. 2003 and Le Jambre et al. 2007). Faecal consistency scores of $1,2,3$ and 4 had a dry matter percent of 20.9, 16.3, 9.6 and 5.8 respectively (Bellosa et al. 2011). The combination of the probiotic (Streptococcus faecium) and prebiotic (MOS) increased the feed intake and faecal consistency in calves (Morrison et al. 2010). The objective of the present study is to determine faecal consistency by means of scores and analyzing dry matter percent in faeces after feeding synbiotics to the young calves.

The study was carried out during the month of September to November 2017 at National Dairy Research Institute (NDRI), Eastern Regional Station, Kalyani, West Bengal, India. The latitude and longitude position of Kalyani is $22^{\circ} 58^{\prime} 30^{\prime \prime} \mathrm{N}$ and $88^{\circ}$ $26^{\prime} 4$ "E, respectively with hot and humid climatic conditions. The average annual maximum and minimum temperatures is $39^{\circ} \mathrm{C}$ and $12^{\circ} \mathrm{C}$, respectively with average annual rainfall of $1250 \mathrm{~mm}$ and relative humidity of $90 \%$.

Twelve Jersey crossbred calves born in September to November 2017 were selected randomly and divided into two groups: treatment and control, consisting of 6 calves each. All the calves selected were separated immediately after birth from their mother. Animal in the treatment (T) group was offered synbiotics @ 100 $\mathrm{ml} / \mathrm{calf} / \mathrm{day}$, dissolved in whole milk for 42 days while the control (C) group received only whole milk without synbiotics. The calves were fed colostrum and whole milk@1/10 $0^{\text {th }}$ of the body weight through feeding bottles. Besides milk the calves were offered ad lib supply of concentrate, green fodder and water. Synbiotic was formulated using Lactobacillus rhamnosus NCDC $298\left(3.4 \times 10^{9} \mathrm{CFU} / \mathrm{ml}\right)$ and Fructo oligosaccharides (FOS) (10\%), in skimmed milk. It is then incubated for $12-16 \mathrm{~h}$ to get the final product. Feed intake and growth of the calves were recorded on weekly basis throughout the study period. Faecal quality (faecal score, dry matter and lactobacillus count) was analysed during 
the synbiotic feeding period and post feeding period of synbiotics. Faecal scour was recorded daily as $1=$ normal faeces, $2=$ slight liquid consistency, $3=$ denoted moderate diarrhoea and 4 indicated severe diarrhoea (Morrison et al. 2010). For estimating dry matter (\%) and bacterial load count in faeces (log, CFU/g), faecal sample was collected from rectum by using sterile rubber gloves Bacterial load (Lactobacillus sp.) was recovered in the faeces by total plate count in MRS (HiMedia ${ }^{\circledR}$ ) (Hasunuma et al. 2011). The colonies were further confirmed by bacterial morphology and gram staining techniques (Ewaschuk et al. 2004).

All the data were analyzed using SPSS software (Version 20) and Analysis of variance (ANOVA) was carried out accordingly. Pearson's linear correlation method (Steel and Torrie 1980) was used to correlate faecal score to faecal quality (percent faecal dry matter and faecal lactobacillus count).

Feeding synbiotic to the calves had no significant effect on dry matter intake (Table 1). The result was in compliance with the study of Simon et al. (2001). They stated that the non-significant finding was may be due to variations in the individual reactions of the animals. However, significantly higher $(P<0.05)$ total body weight gain and average daily gain (Table 1 ) were found in the synbiotic fed group $(29.08 \pm 0.90 \mathrm{~kg}$ and $323.14 \pm 0.01 \mathrm{~g}$, respectively) during 90 days experimental period. The result was in close correspondence to the findings of Dar et al. (2017) and they stated that higher weight gain may be due to better intestinal microbial balance which leads to efficient digestion and absorption of nutrients from the gastrointestinal tract.

The faecal consistency score of 1 to 3 was reported from both the treatment and control groups which had a median percent dry matter of 22.23, 17.66 and 8.72 respectively. The median for lactobacillus count $(\mathrm{CFU} / \mathrm{g})$ for faecal consistency scores in both the groups were 1,2 and 3 was $1.1 \times 10^{7}, 3.2 \times 10^{7}$ and $2.7 \times 10^{8}$, respectively. The faecal sample with higher numeric scores (3) had high water content, indicating diarrhoea in calves. However, Bellosa et al. (2011) has reported faecal dry matter percent for scores of 1,2, 3 and 4 as 20.9, 16.3, 19.6 and 5.8 respectively when the calves infected with C. parvam. Table 2. Represents the faecal scoring, percent dry matter and Lactobacillus load count in synbiotic fed calves at weekly intervals. No difference in faecal score and dry matter percent has been observed in treatment and control group (Table 2). On the contrary, Kehoe et al. (2008) reported lower faecal scores and scour incidence when probiotics was offered to the calves. No differences were observed for faecal score and percent dry matter in faeces between the treatment and control groups. But, faecal bacteria load count was higher in the calves in the treatment group while Lactobacillus count in faeces was higher $(\mathrm{P}<0.01)$ than the control group even after 42 days of feeding (Table 3,4$)$. The findings are in agreement to Heinrichs et al. (2009) who also reported an increase in Lactobacillus count in faeces of calves when the respective synbiotic formula were fed.

Table 1 Dry matter intake and body weight gain of the experimental calves up to 90 days period

\begin{tabular}{lllc}
\hline S.N & Parameters & Control & Treatment \\
\hline 1 & DMI/100 kg Body weight & $3.06 \pm 0.19$ & $3.01 \pm 0.16$ \\
2 & Total body weight gain in 90 days $(\mathrm{kg})$ & $23.58 \pm 2.38^{\mathrm{x}}$ & $29.08 \pm 0.90^{\mathrm{y}}$ \\
3 & Average daily gain in 90 days $(\mathrm{g})$ & $262.03 \pm 0.03^{\mathrm{x}}$ & $323.14 \pm 0.01^{\mathrm{y}}$ \\
\hline
\end{tabular}

${ }^{\mathrm{xy}}$ Differences in superscript in row indicate significance at $P<0.05$

Table 2 Weekly changes in the faecal scoring (1 to 4), faecal dry matter (\%) and bacterial load in faeces (CFU/g) of the experimental calves

\begin{tabular}{|c|c|c|c|c|c|c|}
\hline \multirow[t]{2}{*}{$\overline{\text { Days }}$} & \multicolumn{2}{|c|}{ Fecal score (1-4) } & \multicolumn{2}{|c|}{ Dry matter (\%) } & \multicolumn{2}{|c|}{ Bacterial load $(\log , \mathrm{CFU} / \mathrm{g})$} \\
\hline & Control & Treatment & Control & Treatment & Control & Treatment \\
\hline 7 & $1.40 \pm 0.32$ & $1.02 \pm 0.16$ & $23.37 \pm 3.44$ & $26.02 \pm 2.75$ & $5.39 \pm 0.20$ & $6.56 \pm 0.71$ \\
\hline 14 & $1.07 \pm 0.04$ & $1.00 \pm 0.22$ & $30.67 \pm 1.65$ & $25.63 \pm 3.33$ & $5.62 \pm 0.69$ & $6.82 \pm 0.52$ \\
\hline 21 & $1.33 \pm 0.25$ & $1.35 \pm 0.16$ & $21.99 \pm 2.03$ & $22.44 \pm 3.63$ & $4.60 \pm 0.61$ & $5.98 \pm 0.46$ \\
\hline 28 & $1.14 \pm 0.07$ & $1.25 \pm 0.17$ & $31.20 \pm 4.47$ & $21.06 \pm 1.13$ & $4.40 \pm 0.54$ & $5.63 \pm 0.38$ \\
\hline 35 & $1.45 \pm 0.18$ & $1.21 \pm 0.02$ & $19.40 \pm 0.79$ & $22.39 \pm 1.62$ & $4.97 \pm 0.70$ & $7.02 \pm 0.48$ \\
\hline 42 & $1.30 \pm 0.14$ & $1.19 \pm 0.01$ & $21.64 \pm 1.20$ & $23.86 \pm 1.73$ & $5.21 \pm 0.67$ & $6.25 \pm 0.39$ \\
\hline 49 & $1.07 \pm 0.04$ & $1.38 \pm 0.32$ & 21.641 .28 & $20.34 \pm 0.89$ & $5.44 \pm 0.35$ & $6.88 \pm 0.25$ \\
\hline 56 & $1.21 \pm 0.15$ & $1.33 \pm 0.22$ & $23.42 \pm 2.14$ & $20.60 \pm 1.25$ & $5.04 \pm 0.31$ & $6.11 \pm 0.51$ \\
\hline 63 & $1.19 \pm 0.16$ & $1.19 \pm 0.15$ & $19.68 \pm 0.63$ & $22.28 \pm 2.25$ & $4.71 \pm 0.31$ & $5.71 \pm 0.53$ \\
\hline 70 & $1.69 \pm 0.20$ & $1.16 \pm 0.16$ & $18.27 \pm 0.70$ & $24.28 \pm 2.16$ & $4.61 \pm 0.31$ & $5.12 \pm 0.43$ \\
\hline 77 & $1.38 \pm 0.19$ & $1.50 \pm 0.20$ & $20.39 \pm 0.70$ & $19.04 \pm 1.02$ & $5.22 \pm 0.40$ & $5.56 \pm 0.22$ \\
\hline 84 & $1.57 \pm 0.18$ & $1.16 \pm 0.21$ & $20.02 \pm 1.72$ & $20.71 \pm 0.85$ & $4.58 \pm 0.37$ & $5.26 \pm 0.25$ \\
\hline 90 & $1.33 \pm 0.21$ & $1.16 \pm 0.16$ & $21.37 \pm 1.03$ & $20.65 \pm 0.69$ & $3.17 \pm 0.45$ & $4.86 \pm 0.12$ \\
\hline Overall & $1.32 \pm 0.05$ & $1.24 \pm 0.44$ & $22.54 \pm 0.67$ & $22.25 \pm 0.05$ & $4.84 \pm 0.40$ & $5.98 \pm 0.13$ \\
\hline
\end{tabular}


Table 3 Faecal characteristics of the experimental calves during synbiotic feeding period of (42days) and after 42 up to 90 days period

\begin{tabular}{llllc}
\hline Parameters & \multicolumn{2}{c}{ Faecal score (1-4) } & \multicolumn{2}{c}{ Dry matter (\%) } \\
\cline { 2 - 5 } Days & $\begin{array}{l}\text { Feeding period } \\
\text { (4-42 days) }\end{array}$ & $\begin{array}{l}\text { Post feeding period } \\
\text { (43-90 days) }\end{array}$ & $\begin{array}{l}\text { Feeding period } \\
(4-42 \text { days })\end{array}$ & $\begin{array}{c}\text { Post feeding period } \\
\text { (43-90 days) }\end{array}$ \\
\hline Control & $1.35 \pm 0.06$ & $1.27 \pm 0.06$ & $20.68 \pm 0.50$ & $21.13 \pm 0.54$ \\
Treatment & $1.28 \pm 0.07$ & $1.21 \pm 0.08$ & $24.71 \pm 1.25$ & $23.57 \pm 1.00$ \\
Overall & $1.32 \pm 0.05$ & $1.24 \pm 0.45$ & $22.54 \pm 0.67$ & $22.25 \pm 0.05$ \\
Sig. & & NS & & NS \\
\hline
\end{tabular}

$* * \mathrm{P}<0.01$ significance

Table 4 Faecal Lactobacillus load count (log CFU/g) during synbiotic feeding period and post feeding period in experimental calves

\begin{tabular}{llc}
\hline Parameters & Faecal lactobacillus load count $(\log$ CFU/ml) & \\
\hline Days & Feeding period (4-42 days) & Post feeding period (43-90 days) \\
Control & $4.68 \pm 0.16$ & $5.64 \pm 0.16$ \\
Treatment & $5.03 \pm 0.23$ & $6.38 \pm 0.20$ \\
Overall & $4.84 \pm 0.40$ & $5.98 \pm 0.13$ \\
Sig. & $* *$ & \\
\hline
\end{tabular}

$* * \mathrm{P}<0.01$ significance

Table 5 Correlation between Faecal score with percent dry matter and bacterial load

\begin{tabular}{llll}
\hline Parameter & Faecal score & Dry matter & Bacterial load \\
\hline Faecal score & 1 & & \\
Dry matter & $-0.564^{* *}$ & 1 & 1 \\
Bacterial load & -0.072 & 0.012 & 1 \\
\hline
\end{tabular}

$* * \mathrm{P}<0.01$

Not only between groups, weekly variation $(\mathrm{p}<0.01)$ in percent dry matter in faeces and faecal Lactobacillus load count has been found within the groups.

The faecal score was negatively correlated $(r=-0.564, \mathrm{P}<0.01)$ to percent dry matter content in faeces while bacterial (Lactobacillus sp.) load count recovered in faeces was negatively correlated $(\mathrm{r}=0.072)$ to the faecal score and positively correlated $(\mathrm{r}=0.012)$ to the dry matter percent in faeces (Table 5). The lower dry matter percent in faeces reflects the incidence of diarrhoea in calves. Similar trend was reported by Bellosa et al. (2011) and Agazzi et al. (2015) in calves fed probiotics and synbiotics, respectively. The faecal score was found to be higher in the first two weeks of life which then decreased at $3^{\text {rd }}$ week and became normal by $4^{\text {th }}$ and $5^{\text {th }}$ week of age. Similar findings were reported by Bayatkouhsar et al. (2013) however, Quezadamendoza et al. (2011) did not find any effect of probiotics on diarrhoea.

\section{Conclusions}

Hence faecal quality (faecal score, faecal dry matter and bacterial load) improved when synbiotics was fed to the neonatal calves. Further investigation with larger sample size over extended period of synbiotic feeding is necessary to give us the true picture of the trial.

\section{Acknowledgements}

The authors are thankful to the Head, ICAR- National Dairy Research Institute, Eastern Regional Station, Kalyani, West Bengal, India for providing necessary facilities for conducting the study.

\section{References}

Agazzi A, Tirloni E, Stella S, Maroccolo S, Ripamonti B, Bersani C, Savoini G (2014) Effects of species-specific probiotic addition to milk replacer on calf health and performance during the first month of life. Ann Anim Sci 14: 101-115

Anand S, Mandal S, Tomar SK (2017) Effect of Lactobacillus rhamnosus NCDC 298 with FOS in combination on viability and toxin production of enterotoxigenic Escherichia coli. Probiotics and Antimicrobial Proteins 1-7

Bayatkouhsar J, Tahmasebi AM, Naserian AA, Mokarram RR, Valizadeh R (2013) Effects of supplementation of lactic acid bacteria on growth performance, blood metabolites and fecal coliform and lactobacilli of young dairy calves. Anim Feed Sci Technol 186: 1-11

Bellosa ML, Nydam DV, Janice LL, Zambriski JA, Linden TC, Bowman D (2011) A comparison of faecal percent dry matter and number of Cryptosporidium parvum oocyst shed to observational faecal consistency scoring in dairy calves. J Parasitol 97: 349-351

Dar A, Singh S, Palod J, Ain K, Kumar N, Farooq F, Khadda B (2017) Effect of probiotic, prebiotic and synbiotic on hematological parameters of crossbred calves. Int J Livest Res 7: 128-136

Heinrichs AJ, Jones CM, Elizondo-Salazar JA, Terrill SJ (2009) Effects of a prebiotic supplement on health of neonatal dairy calves. Livest Sci 125: 149-154 
Kehoe SI, Heinrichs AJ, Baumrucker CR, Greger DL (2008) Effects of nucleotide supplementation in milk replacer on small intestinal absorptive capacity in dairy calves. J Dairy Sci 91: 27590-2770

Le Jambre, Dominic LFS, Eady SJ, Henshall, Colditz IG (2007) Adjusting worm egg counts for faecal moisture in sheep. Vet Parasitol 145: 108-115.

Mandal S, Anand S (2016) Combating secretory diarrhea: Formulation of an effective 'Synbiotic'. NDRI News 21: 2

Marcondes, MI, Pereira TR, Chagas JCC, Filgueiras EA, Castro MMD, Costa GP, Sainz RD. (2016) Performance and health of Holstein calves fed different levels of milk fortified with symbiotic complex containing pre-and probiotics. Trop Anim Health Prod 48: 15551560.

Moore DA, Atwill ER, Kirk JH, Brahmbhatt D, Alonso LH, Hou L, Singer MD, Miller TD. (2003) Prophylactic use of deconquinate for infections with Cryptsporidium parvam in experimentrally challenged neonatal calves. J Am Vet Med Assoc 223: 839-845

Moran J (2002) Calf rearing: A practical guide. Collingwood: Land Links.

Morrison SJ, Dawson S, Carson AF (2010) The effects of mannan oligosaccharide and Streptococcus faecium addition to milk replacer on calf health and performance. Livest Sci 131: 292-296.

Pranckute R, Kaunietis A, Kuisiene N, Citavicius DJ (2016) Combining prebiotics with probiotic bacteria can enhance bacterial growth and secretion of bacteriocins. Int J Biol Macromol 89: 669-676
Ewaschuk JB, Naylor JM, Chirino-Trejo M, Zello GA (2004). Lactobacillus rhamnosus strain GG is a potential probiotics for calves. Canadian J Vet Res 64: 249-253

Quezada-Mendoza VC, Heinrichs AJ, Jones CM (2011) The effects of a prebiotic supplement (Prebio Support) on fecal and salivary IgA in neonatal dairy calves. Livest Sci 142: 222-228

Hasunuma T, Kawashima K, Nakayama H, Murakami T, Kanagawa H, Ishii T, Kushibiki S, (2011) Effect of cello oligosaccharide or synbiotic feeding on growth performance, fecal condition and hormone concentrations in Holstein calves. Anim Sci J 8: 2543-548

Roodposhti PM, Dabiri N (2012) Effects of Probiotic and Prebiotic on Average Daily Gain, Fecal Shedding of Escherichia Coli, and Immune System Status in Newborn Female Calves. Asian-Australas J Anim Sci 25: 1255-1261

Simon O, Jadamus A, Vahjen W (2001) Probiotic feed additiveseffectiveness and expected modes of action. J Anim Feed Sci 10: 51-68

Steel RGD, Torrie JH (1980) Principles and procedures of Statistics- A Biometrical Approach, $2^{\text {nd }}$ Edn. McGraw Hill Inter. Book Co. Tokyo, Japan 